\title{
NEW REFERENCE APOLLO3® CALCULATION SCHEME FOR LIGHT WATER REACTORS - ANALYSIS OF THE BEAVRS BENCHMARK
}

\author{
Jean-François Vidal ${ }^{1}$, K. Frölicher ${ }^{1}$, P. Archier ${ }^{1}$, A. Hébert ${ }^{2}$, L. Buiron ${ }^{1}$, \\ J-M. Palau ${ }^{1}$, S. Pastoris ${ }^{1}$, D. Raynaud ${ }^{1}$ \\ ${ }^{1}$ Commissariat à l'Energie Atomique et aux Energies Alternative \\ DEN, DER/SPRC, Cadarache F-13108 Saint-Paul-lez-Durance, France \\ ${ }^{2}$ Ecole Polytechnique de Montréal, Institut de Génie Nucléaire \\ P. O. Box 6079, Station “Centre-Ville”, Montréal, Q. C., Canada \\ jean-francois.vidal@cea.fr
}

\begin{abstract}
In the past few years, developments in the APOLLO $3^{\circledR}$ deterministic code have mainly been devoted to Fast Reactor applications. In this paper, we investigate the possibility of using some of these methods to build an accurate two-step calculation scheme for commercial Pressurized Water Reactors, with application to the BEAVRS benchmark at hot zero power conditions of cycle 1. Our objective is to assess the performances of the best "standard" calculation currently possible with $\mathrm{APOLLO} 3^{\circledR}$ and to have a starting point for the development of improved transport solvers and innovative calculation schemes.

At the lattice level, we show that the subgroup method using the REL383 energy mesh, associated with a MOC flux calculation, provides accurate results on different clusters of $3 \times 3$ cells with UOX and MOX fuel, including a heterogeneity at the center (guide-tube full of water or with common absorbers Ag-In-Cd or B4C inserted, and mixed uranium-gadolinium oxide fuel). These good results have been confirmed on BEAVRS assembly, rods in and rods out.

At the core level, 20-group 3D calculations with the MINARET Sn solver have been performed at the cell level to analyze BEAVRS Hot Zero Power results (reactivity, power map, and control rods worths). Results are rather satisfactory, considering the low computing cost, but the power map prediction needs to be improved.
\end{abstract}

KEYWORDS: APOLLO3 ${ }^{\circledR}$, Sn transport, PWR, BEAVRS

\section{INTRODUCTION}

In the past few years, developments in the APOLLO $3^{\circledR}$ code [1] have mainly been devoted to Fast Reactor applications:

- At the lattice level: subgroup and Tone's self-shielding methods [2], exact B-heterogeneous leakage model and flux moments weighting homogenization [3], 3D TDT-MOC solver [4] and 2D-MOC/1DSn fusion method for 3D assembly homogenization [5],

- At the core level: unstructured Sn solver MINARET allowing to perform Sn 3D transport calculations on heterogeneous geometries [6]. 
In this paper, we investigate the possibility of using some of these methods to build an accurate two-step calculation scheme for commercial Pressurized Water Reactors, with application to the BEAVRS benchmark at hot zero power conditions of cycle 1. Our objective is to assess the performances of the best "standard" calculation currently possible with APOLLO3 ${ }^{\circledR}$ and to have a starting point for the development of improved transport solvers and innovative calculation schemes.

The performances of APOLLO $3^{\circledR}$ self-shielding methods for UOX and MOX fuel have been studied recently. The results reported in [7] show that the subgroup method using the REL383 energy mesh followed by a MOC flux calculation provides accurate results in various situations and can be considered as a reference for LWR lattice calculations. In this paper (chapter 3), the validation is first extended to usual absorbers as Ag-In-Cd (Silver-Indium-Cadmium), B4C (boron carbide), and mixed uraniumgadolinium oxide fuel, on a $3 \times 3$ cell cluster. Then, in a second step, the numerical validation is performed on BEAVRS assembly calculations [8], control rods inserted or not. Chapter 4 will show first full-core results for BEAVRS Hot Zero Power conditions. The second chapter first presents the two-step APOLLO3-LWR calculation scheme as applied to BEAVRS.

\section{APOLLO3-LWR CALCULATION SCHEME}

\subsection{Lattice Step}

The 2D lattice calculations provide self-shielding and homogenized cross sections for the different assemblies to be used in full-core 3D calculations. A 383-group energy mesh has been derived from the 361-group SHEM mesh proposed by Hebert and Santamarina [9] to perform self-shielding calculations in UOX and MOX fuels with the subgroup method (between $5.5 \mathrm{eV}$ and $11.4 \mathrm{keV}$ ), the Tone's method being sufficient for treating the upper part of the energy domain (unresolved resonance range of heavy nuclei). In [7], we have shown that at low energy, the mixture treatment associated with the subgroup method (probability tables calculated on the fly) gives more accurate results against continuous energy Monte Carlo treatment with TRIPOLI- $4{ }^{\circledR}[10]$, reducing the error on UOX cell multiplication factor to less than $100 \mathrm{pcm}(200 \mathrm{pcm}$ for MOX).

The flux calculation is carried out using the Method of Characteristics of the TDT-MOC solver (with the constant source approximation) on a refined mesh (see Fig. 1). The tracking parameters of the MOC have been optimized (48 angles $\in[0, \pi]$ for the cyclic azimuthal quadrature, 3 angles $\in[0, \pi / 2]$ for the Bickley-type polar quadrature, uniform track density of $100 \mathrm{~cm}^{-1}$ ). The scattering anisotropy is $\mathrm{P}$.

The same options are used for the calculation of the usual absorbers (AIC, B4C, Gd) with a mixture treatment applied on silver isotopes $\left({ }^{107} \mathrm{Ag}\right.$ and $\left.{ }^{109} \mathrm{Ag}\right)$ to take account of overlapping resonances.

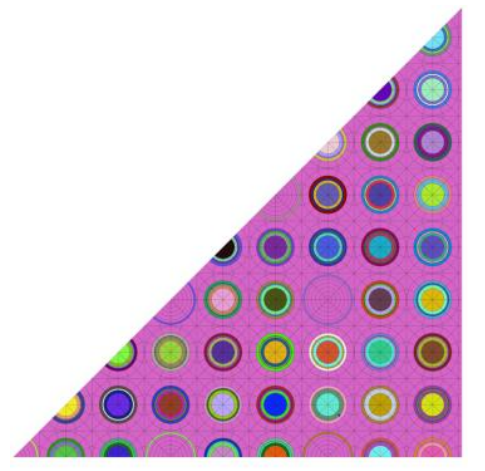

Figure 1. TDT/MOC spatial mesh for $1 / 8^{\text {th }}$ of a BEAVRS assembly. 
A cell-by-cell homogenization and a 20-group collapsing are necessary to limit the number of unknowns in the full-core calculation. For the radial reflector, two sets of homogenized cross-sections, for the steel baffle and water, are obtained from two pseudo-1D traverse calculations at $0^{\circ}$ and $45^{\circ}$ to take account of the variation in water thickness between the baffle and the core barrel. 3x17 fuel cells are feeding the reflector described as a succession of slabs of homogeneous media (one of the traverse is shown Fig. 2).

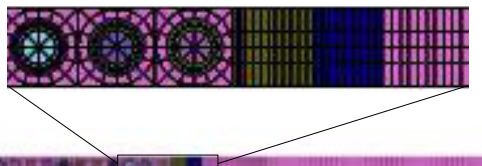

Figure 2. TDT/MOC spatial mesh for a BEAVRS traverse.

The cross sections of the axial reflector are obtained by a 1D Sn calculation using homogeneous media for the fuel (obtained in a preliminary calculation) and the different structures above the active region.

Two methods are used for the homogenization: the standard flux-weighting method and the flux-moment weighting method [3]; they will be compared on full-core calculations (chapter 4).

\subsection{Core Calculation}

The Discontinuous-Galerkin Finite Element Method of the MINARET Sn-solver lies on an axially extruded triangular mesh. In the core, two triangles are needed to represent each homogenized cell. Thanks to the unstructured mesh, the baffle, the reflector, the core barrel and the neutron shield panels of BEAVRS can be exactly described. The radial mesh size can be relaxed in and beyond the core barrel, limiting the number of mesh to 60000 in the radial plane (Fig. 3 shows one quarter of core with a zoom on the core-reflector interface). Axially, the grids are explicitly described and the maximal size mesh is 10 $\mathrm{cm}$, leading to 54 axial planes. The finite elements are parabolic in the XY plan and in the Z direction. Thus, the total number of spatial unknowns is close to 26 million. The Sn quadrature is a product quadrature (Gauss-Chebyschev with 98 directions) and the scattering anisotropy is P3.
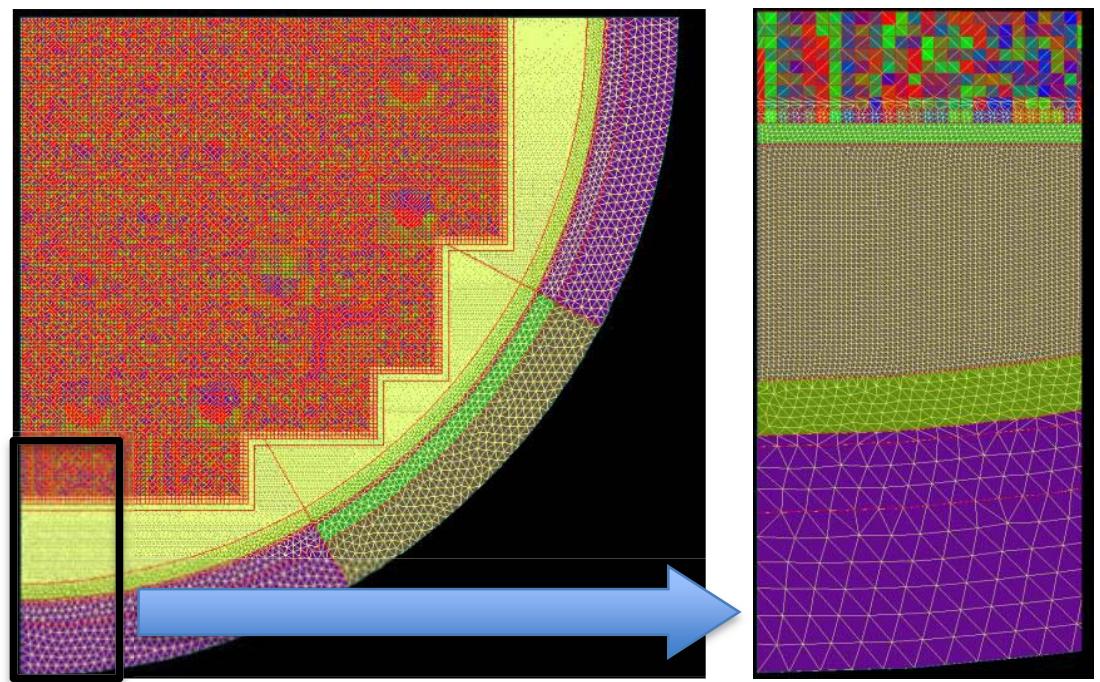

Figure 3. MINARET full-core radial spatial mesh. 


\section{VALIDATION OF THE LATTICE CALCULATIONS}

\subsection{Clusters Fissile-Absorber}

The validation has been carried on a $3 \times 3$ cell-cluster with the absorber in the center surrounded by eight fuel cells, UOX or MOX (cf. Fig. 4). The AIC and B4C absorbers are divided into four rings, the Gadolinium one into ten. The absorbers efficiency is calculated by the difference of the reactivities between the configurations with and without absorber (ABS) in the central guide-tube (GT):

$$
\Delta \rho^{A B S}(p c m)=10^{5} \times\left[\left(1 / k_{\infty}\right)^{G T}-\left(1 / k_{\infty}\right)^{A B S}\right],
$$

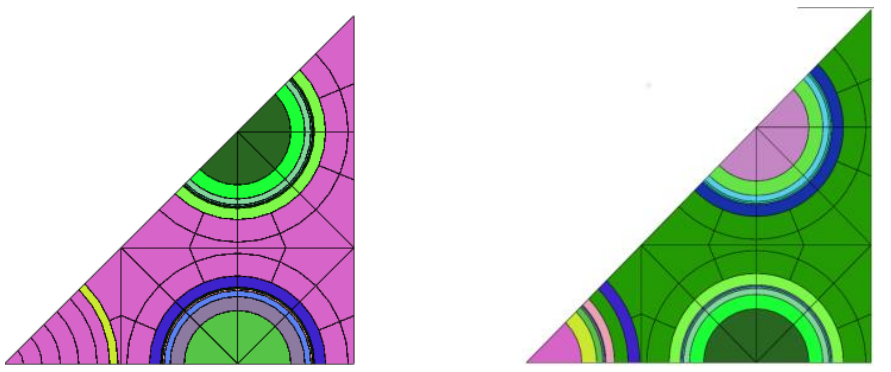

Figure 4. Guide-tube (on the left) and absorber (on the right) clusters $\left(1 / 8^{\text {th }}\right.$ symmetry).

Table I compares the results of APOLLO $3^{\circledR}$ with the results of TRIPOLI- $4^{\circledR}$, for the subgroup method and the Sanchez-Coste method inherited from APOLLO2. With a maximum of $0.8 \%$ discrepancy, the subgroup method is always more accurate than the Sanchez-Coste one. AIC worth calculation is particularly improved for MOX fuel.

Table I. LWR-absorbers in UOX and MOX clusters: APOLLO $3^{\circledR} /$ TRIPOLI- $4{ }^{\circledR}$ comparisons on reactivity worth.

\begin{tabular}{|c|c|c|c|c|c|c|}
\hline & & \multicolumn{3}{|c|}{ UOX } & \multicolumn{2}{|c|}{ MOX } \\
\hline & & Gd & AIC & B4C & $\mathbf{A I C}$ & B4C \\
\hline & T4 worth (pcm) & 27473 & 50910 & 58150 & 29715 & 37308 \\
\hline \multirow[t]{2}{*}{$\Delta \rho^{A B S}(A 3 / T 4)$} & Sanchez-Coste & $0.78 \%$ & $1.24 \%$ & $0.52 \%$ & $2.06 \%$ & $0.68 \%$ \\
\hline & Subgroup & $0.66 \%$ & $0.80 \%$ & $0.39 \%$ & $0.62 \%$ & $0.09 \%$ \\
\hline
\end{tabular}

\subsection{BEAVRS Assemblies}

The APOLLO3-LWR calculation scheme has been applied to BEAVRS assemblies. The infinite multiplication factors and the absorbers worth comparisons with TRIPOLI- ${ }^{\circledR}$ (including burnable absorbers BA) are reported for the 3.1 enriched assembly in Table II. The infinite multiplication factors are in rather good agreement with a slight underestimation in most cases. The largest discrepancy is observed for the SIC absorber $(-300 \mathrm{pcm})$. The absorbers efficiency is well calculated (better than $0.7 \%)$. The same trends are obtained for the other enrichments $(2.4$ and $1.6 \mathrm{w} / \mathrm{o})$. 
Table II. BEAVRS 3.1 enriched assembly:

APOLLO $3^{\circledR} /$ TRIPOLI $-4^{\circledR} \mathrm{k}_{\infty}$ and reactivity worth comparisons.

\begin{tabular}{|l|c|c|c|c|c|c|c|c|}
\hline Configuration & 0BA & $\begin{array}{c}\text { 0BA } \\
\text { B4C }\end{array}$ & $\begin{array}{c}\text { 0BA } \\
\text { AIC }\end{array}$ & 6BA & $12 \mathrm{BA}$ & $15 \mathrm{BA}$ & $16 \mathrm{BA}$ & $20 \mathrm{BA}$ \\
\hline $\mathrm{k}_{\infty} \mathrm{T} 4$ & 1.23045 & 0.80924 & 0.87074 & 1.17315 & 1.11125 & 1.08836 & 1.07345 & 1.03759 \\
\hline $1 \sigma \mathrm{T} 4(\mathrm{pcm})$ & 4 & 3 & 3 & 5 & 4 & 4 & 4 & 4 \\
\hline$\Delta \rho \mathrm{AP} 3 / \mathrm{T} 4(\mathrm{pcm})$ & -79 & 4 & -302 & -92 & -122 & -127 & -127 & -137 \\
\hline$\rho \mathrm{ABS}-\mathrm{T} 4(\mathrm{pcm})$ & & -42302 & -33573 & -3970 & -8718 & -10611 & -11886 & -15107 \\
\hline $1 \sigma \mathrm{T} 4(\mathrm{pcm})$ & & 6 & 5 & 7 & 6 & 6 & 6 & 6 \\
\hline$\Delta \rho \mathrm{ABS}(\mathrm{AP} 3-\mathrm{T} 4) / \mathrm{T} 4$ & & $-0.2 \%$ & $0.7 \%$ & $0.3 \%$ & $0.5 \%$ & $0.4 \%$ & $0.4 \%$ & $0.4 \%$ \\
\hline
\end{tabular}

\section{CORE VALIDATION ON BEAVRS BENCHMARK AT HZP}

\subsection{Reactivity}

In the BEAVRS model, five different critical configurations are provided from the all rods out (ARO) configuration to the all banks inserted one (i.e, the seven banks D, C, B, A, SE, SD and SC).

The APOLLO3-MINARET results using the two homogenization methods, flux and moments, are compared to the measurement data and to some published results obtained with Monte Carlo codes (SuperMC [11], OpenMC [12], MVP [13]) and deterministic 2D/1D codes (nTRACER[14] and MPACT [15]). Different nuclear data evaluation are used (ENDF/BVII.0, ENDF/BVII.1, JENDL4.0, and JEFF3.1.1 for our calculations).

Table III shows the results for the criticality (Monte Carlo standard deviations are omitted but can be found in the referenced papers, they are generally less than a few $\mathrm{pcm}$ ). We can observe that the eigenvalues computed by APOLLO3 ${ }^{\circledR}$ are the lowest, they are underestimated in a range of $[-100 ;-450]$ pcm.

Table III. Keff results for the HZP critical configurations and distances to the ARO one

\begin{tabular}{|c|c|c|c|c|c|c|c|}
\hline Code & MVP-3b & SuperMC & OpenMC & MPACT & nTRACER & $\begin{array}{l}\text { APOLLO3 } \\
\text { flux } \\
\end{array}$ & $\begin{array}{c}\text { APOLLO3 } \\
\text { moments }\end{array}$ \\
\hline Config. ${ }^{\text {Library }}$ & JENDL-4.0 & B-VII.1 & B-VII.0 & B-VII.0 & B-VII.0 & JEFF3.1.1 & JEFF3.1.1 \\
\hline $\begin{array}{l}\text { ARO } \\
\quad(975 \mathrm{ppm})\end{array}$ & 1.00026 & 1.00032 & 0.9992 & 0.99819 & 0.99967 & 0.99738 & 0.99751 \\
\hline \multirow{2}{*}{$\begin{array}{l}\mathrm{D} \text { in } \\
\quad(902 \mathrm{ppm})\end{array}$} & 1.00179 & 1.00204 & 1.0008 & 0.99972 & 1.00127 & 0.99891 & 0.99906 \\
\hline & $153 \mathrm{pcm}$ & $172 \mathrm{pcm}$ & $160 \mathrm{pcm}$ & $153 \mathrm{pcm}$ & $160 \mathrm{pcm}$ & $154 \mathrm{pcm}$ & $156 \mathrm{pcm}$ \\
\hline \multirow{2}{*}{$\begin{array}{l}\mathrm{C}, \mathrm{D} \text { in } \\
\quad(810 \mathrm{ppm})\end{array}$} & 1.00103 & 1.00139 & 1.00023 & 0.99913 & 1.00068 & 0.99813 & 0.99845 \\
\hline & $77 \mathrm{pcm}$ & $107 \mathrm{pcm}$ & $103 \mathrm{pcm}$ & $94 \mathrm{pcm}$ & $101 \mathrm{pcm}$ & $75 \mathrm{pcm}$ & $94 \mathrm{pcm}$ \\
\hline \multirow{2}{*}{$\begin{array}{r}\mathrm{A}, \mathrm{B}, \mathrm{C}, \mathrm{D} \text { in } \\
(686 \mathrm{ppm})\end{array}$} & 0.99938 & 0.99995 & 0.99884 & 0.99769 & 0.99931 & 0.9963 & 0.99683 \\
\hline & $-88 \mathrm{pcm}$ & $-37 \mathrm{pcm}$ & $-36 \mathrm{pcm}$ & $-50 \mathrm{pcm}$ & $-36 \mathrm{pcm}$ & $-109 \mathrm{pcm}$ & $-68 \mathrm{pcm}$ \\
\hline \multirow{2}{*}{$\begin{array}{l}\mathrm{A}, \mathrm{B}, \mathrm{C}, \mathrm{D}, \mathrm{SE}, \\
\mathrm{SD}, \mathrm{SC} \text { in } \\
\quad(508 \mathrm{ppm})\end{array}$} & 0.99798 & 0.99841 & 0.99725 & 0.9966 & 0.99816 & 0.99468 & 0.99551 \\
\hline & $-228 \mathrm{pcm}$ & $-191 \mathrm{pcm}$ & $-196 \mathrm{pcm}$ & $-160 \mathrm{pcm}$ & $-151 \mathrm{pcm}$ & $-272 \mathrm{pcm}$ & $-201 \mathrm{pcm}$ \\
\hline
\end{tabular}


The distance from keff $=1.00000$ is depending on the one hand on nuclear data and on the other hand on modeling. Thus, the absolute value of the errors do not make it possible to directly evaluate the quality of the modeling; it is more interesting to compare the differences between the rodded configurations and the ARO one. When doing so, we can see that, for each configuration, the differences are relatively close regardless the computing code used. The flux-moment homogenization of APOLLO ${ }^{\circledR}$ slightly reduces this difference when many banks are inserted compared to the standard scalar flux weighting.

\subsection{Control rod bank worth}

The BEAVRS benchmark provides the control rods worth for each of the seven banks but only the five critical boron concentrations of Table III are known. Therefore, instead of estimating the unknown concentrations, we preferred to sum the effects when going from a critical configuration to another one. This concerns the banks $\mathrm{A}+\mathrm{B}$ and the banks $\mathrm{SE}+\mathrm{SD}+\mathrm{SC}$. The control rod bank worths are then calculated as the reactivity variation produced by the full insertion of the control rod bank(s) from the top position. Two values are obtained by considering the critical boron concentrations of the initial state and of the final one. We took the average, as shown in Eq. 2:

$$
\Delta \rho=\frac{1}{2}\left[\Delta \rho_{\text {init } C b}+\Delta \rho_{\text {final } C b}\right]=\frac{1}{2}\left[\left(\frac{1}{k_{\text {init } C b}^{\text {down }}}-\frac{1}{k_{\text {init } C b}^{u p}}\right)+\left(\frac{1}{k_{\text {final } C b}^{\text {down }}}-\frac{1}{k_{\text {final } C b}^{u p}}\right)\right] \cdot 10^{5},
$$

In Table IV, we can observe that APOLLO $3^{\circledR}$ results agree well with the measurements with a maximum difference less than $3.9 \%$ when using the flux-moments homogenization technique $(5.6 \%$ with the scalar flux). They are comparable to those obtained with the Monte Carlo and the other deterministic codes.

Table IV. Calculations differences with measured data for the control rod bank worths

\begin{tabular}{|l|c|c|c|c|c|c|c|c|}
\hline Bank(s) inserted & $\begin{array}{c}\text { Measure } \\
\text { value (pcm) }\end{array}$ & MVP-3b & SuperMC & OpenMC & MPACT & nTRACER & $\begin{array}{c}\text { APOLLO3 } \\
\text { flux }\end{array}$ & $\begin{array}{c}\text { APOLLO3 } \\
\text { moments }\end{array}$ \\
\hline D & 788 & $-0.1 \%$ & $-1.1 \%$ & $-2.2 \%$ & $-1.0 \%$ & $-0.8 \%$ & $0.5 \%$ & $0.1 \%$ \\
\hline C with D in & 1203 & $3.7 \%$ & $5.2 \%$ & $2.6 \%$ & $4.1 \%$ & $2.2 \%$ & $5.6 \%$ & $3.9 \%$ \\
\hline B+A with D, C in & 1719 & $1.6 \%$ & $1.6 \%$ & $2.0 \%$ & $1.4 \%$ & $2.7 \%$ & $3.9 \%$ & $2.5 \%$ \\
\hline $\begin{array}{l}\text { SD+SC+SE with } \\
\text { D, C, B, A in }\end{array}$ & 2332 & $2.2 \%$ & $4.5 \%$ & $2.7 \%$ & $-0.8 \%$ & - & $4.5 \%$ & $2.9 \%$ \\
\hline
\end{tabular}

\subsection{Power distribution}

The radial power distribution was measured for the ARO configuration by using ${ }^{235} \mathrm{U}$ fission chambers inserted into the central instrumentation tube of 58 assemblies. The BEAVRS measured data presents a very large NW-SE (10\%) tilt at HZP conditions that cannot be explained by detector measurements alone, since the core loading pattern is known to be symmetric. A tilt-corrected distribution has been proposed in the revision 2.0.2 of the benchmark specifications so that the resulting radial map is eighth-core symmetric. The APOLLO $3{ }^{\circledR}$ fission rate distributions are compared to this tilt-corrected distribution in Fig. 5. A radial tilt is observed with an underestimation of the power at the center of the core (by 0.5 to $2.5 \%$ with the scalar flux homogenization) and an overestimation at the periphery (between 2.5 and $4.0 \%)$. This tilt is increased when using the flux-moment weighting. The reflector effect seems too important and this problem is under investigation: a Monte Carlo modelization with TRIPOLI-4 is in progress to try to distinguish what comes from the nuclear data from what comes from the deterministic model (homogenization/condensation biases, reflector model). 
$\begin{array}{llllllll}\text { H } & \text { G } & \text { F } & \text { E } & \text { D } & \text { C } & \text { B } & \text { A }\end{array}$

\begin{tabular}{|l|l|l|l|l|} 
Tilt-corrected Data (normalized to the 58 meas. assemblies) & & 0.854 & 0.704 \\
C/E-1 [\%] APOLLO3 with scalar flux homogenization & & $6.3 \%$ & $3.9 \%$ \\
C/E-1 [\%] APOLLO3 with flux-moment homogenization & & $7.9 \%$ & $5.6 \%$ \\
\hline
\end{tabular}

Figure 5. APOLLO3-MINARET differences with tilt-corrected measurement data $\left(1 / 8^{\text {th }}\right.$ core symmetry)

\section{CONCLUSIONS}

In this paper, we build a two-step calculation scheme for full-core Pressurized Water Reactors, using the best methods currently available in APOLLO3 ${ }^{\circledR}$, at the lattice step (subgroup ECCO-like self-shielding method and TDT/MOC solver), and at the core step (MINARET Sn solver). Our objective is to evaluate the performances of the best "classical" calculation currently possible with APOLLO ${ }^{\circledR}$ and to have a starting point for the development of improved transport solvers and innovative calculation schemes.

At the lattice step, we observe a very good agreement against reference Monte Carlo calculations (reactivity of UOX fuel predicted within $100 \mathrm{pcm}$, standard absorbers worth predicted within $0.8 \%$ ).

At the core level, the analysis of BEAVRS Cycle 1 HZP measurements shows that the reactivity and the control rod worth are rather well calculated compared to published Monte Carlo and deterministic results when using the flux-moment homogenization, and for a low computational cost ( 1 day of computation on a 20 cores desktop, including 5 hours devoted to the generation of the condensed library). However, the results are less favorable than the standard scalar flux weighting with respect to the power distribution (radial tilt around $8 \%$ against $5 \%$ ).

Further investigations are needed to address this issue, including BEAVRS full-core Monte Carlo simulations with the JEFF3.1.1 library, to uncouple the nuclear data and model biases and perform a validation of the MINARET calculations at the cell level. The following step will be the analysis of the cycle 1 of BEAVRS, introducing thermohydraulic feedback and depletion. 


\section{ACKNOWLEDGMENTS}

APOLLO3 $^{\circledR}$ and TRIPOLI- $4^{\circledR}$ are registered trademarks of CEA. We gratefully acknowledge FRAMATOME and EDF for their long-term partnership and support.

\section{REFERENCES}

1. D. Schneider et al., "APOLLO3 ${ }^{\circledR}$ : CEA/DEN Deterministic Multi-Purpose Code for Reactor Physics Analysis," Proc. Int. Conf. on Physics of Reactors (PHYSOR 2016), Sun Valley, Idaho, USA, May 1$5,(2016)$

2. L. Li Mao, I. Zmijarevic and R. Sanchez, "Resonance Self-Shielding Methods for Fast Reactor Calculations - Comparison of a New Tone's Method with the Subgroup Method in APOLLO3 ${ }^{\circledR}$," Nuclear Science and Engineering, 188(1), pp. 15-32 (2017)

3. J-F. Vidal et al., "APOLLO3 ${ }^{\circledR}$ Homogenization Techniques for Transport Core Calculations Application to the ASTRID CFV Core," Nuclear Engineering and Technology, 49, pp. 1379-1387 (2017)

4. D. Sciannandrone, S. Santandrea, R. Sanchez and L. Li Mao, "Coupled fine-group three dimensional flux calculation and subgroups method for a FBR hexagonal assembly with the APOLLO3 ${ }^{\circledR}$ core physics analysis code," in Proc. Int. Conf. on Mathematics and Computation (M\&C2015), Nashville, Tenesse, USA, April 19-23, (2015)

5. B. Faure, P. Archier, J.-F. Vidal, and L. Buiron, "A 2D/1D Algorithm for Effective Cross-Section Generation in Fast Reactor Neutronic Transport Calculations," Nuclear Science and Engineering, 192(1), pp 40-51 (2018)

6. J-Y. Moller, J-J. Lautard, "MINARET, a Deterministic Neutron Transport Solver for Nuclear Core Calculations," in Proc. Int. Conf. on Math. and Comp. (M\&C2011), Rio de Janeiro, Brazil, May 8-12 (2011).

7. J-F. Vidal, D. Raynaud, "Combining the Tone's and subgroup method for reference self-shielding calculations in APOLLO3 ${ }^{\circledR}$," Proc. Int. Conf. on Physics and Technology of Reactors and Applications (PHYTRA4), Marrakech, Morocco, September 17-19 (2018)

8. N. Horelik, B. Herman, M. Ellis, S. Kumar, J. Liang, B. Forget, K. Smith, "Benchmark for Evaluation And Validation of Reactor Simulations, BEAVRS," RELEASE rev. 2.0.2, MIT Computational Reactor Physics Group, April 11 (2018), https://crpg.mit.edu/sites/default/files/css_injector_images_image/BEAVRS_2.0.2_spec.pdf

9. 14. A. Hébert and A. Santamarina, "Refinement of the Santamarina-Hfaiedh Energy Mesh Between $22.5 \mathrm{eV}$ and $11.4 \mathrm{keV}, "$ Proc. Int. Conf. on Physics of Reactors (PHYSOR2008), Interlaken, Switzerland, September 14-19 (2008).

10. E. Brun et al., "TRIPOLI-4 ${ }^{\circledR}$, CEA, EDF and AREVA reference Monte Carlo code," Annals of Nuclear Energy, 82, pp. 151-160 (2015).

11. Zhiyan Wang et al., "Validation of SuperMC with BEAVRS Benchmark at Hot Zero Power Condition," in Proc. Int. Conf. on Math. and Comp. (M\&C2017), Jeju, Korea, April 16-20 (2017).

12. N. Horelik, B. Herman et al., "Benchmark for Evaluation and Validation of Reactor Simulations (BEAVRS)," Proc. Int. Conf. on Math. and Comp. (M\&C2013), Sun Valley, Idaho, May 5-9 (2013).

13. M. Suzuki, Y. Nauchi, "Analysis of BEAVRS Revision 2.0 LWR Whole Core Calculation Using MVP with JENDL-4.0," in Proc. Int. Conf. on Math. and Comp. (M\&C2017), Jeju, Korea, April 1620 (2017).

14. M. Ryu et al., "Solution of the BEAVRS benchmark using the nTRACER direct whole core transport code," in Proc. Int. Conf. on Physics of Reactors (PHYSOR 20146), Kyoto, Japan, September 28October 3 (2014).

15. B. Collins, A. Godfrey, "Analysis of the BEAVRS benchmark using VERA-CS," Proc. Joint Int. Conf. on Math. and Comp. (M\&C), Supercomputing in Nuclear Application (SNA) and the Monte Carlo (MC) Method, 'MC2015), Nashville, Tennessee, USA, April 19-23 (2015). 